Alicja RAFALSKA-ŁASOCHA

Wydział Chemii UJ

Zakład Chemii Nieorganicznej

rafalska@chemia.uj.edu.pl

\title{
OBCHODY 100. ROCZNICY ŚMIERCI KAROLA STANISŁAWA OLSZEWSKIEGO (1846-1915)
}

\begin{abstract}
Streszczenie
Artykuł poświęcony jest znakomitemu polskiemu uczonemu prof. Karolowi Olszewskiemu, który urodził się i żył, gdy Polska nie istniała na mapie świata, a nauka polska rozwijana była głównie na uniwersytetach w Krakowie, we Lwowie i kilku innych uczelniach na zachodzie Europy. W 1883 roku Karol Olszewski i Zygmunt Wróblewski po raz pierwszy skroplili tlen, azot i tlenek węgla w stanie statycznym. Olszewski skroplił również wodór w stanie dynamicznym (1884).

W styczniu 1896 roku, po przeczytaniu pracy W. Roentgena o nowym rodzaju promieniowania, profesor Olszewski zbudował zestaw i otrzymał w Krakowie promienie X. Wydarzenie to dało początek polskiej radiologii.

Karol Olszewski zmarł 25 marca 1915 roku. W marcu 2015 roku, w 100-lecie śmierci uczonego, Wydział Chemii UJ był inicjatorem i organizatorem uroczystości upamiętniających osobę i naukowe osiągnięcia profesora Karola Olszewskiego.
\end{abstract}

Słowa kluczowe: Karol Olszewski, kriogenika, historia nauki

\section{Wstęp}

Wśród krakowskich uczonych, których naukowe osiągnięcia zapisały się złotymi zgłoskami w historii nauki, znajdziemy z pewnością nazwisko prof. Karola Olszewskiego. Wspólnie z profesorem fizyki Zygmuntem Wróblewskim w 1883 roku po raz pierwszy skroplił on tlen, azot i tlenek węgla. W setną rocznicę śmierci profesora Olszewskiego zorganizowano liczne uroczystości, mające na celu przypomnienie jego osoby i najważniejszych dokonań. 


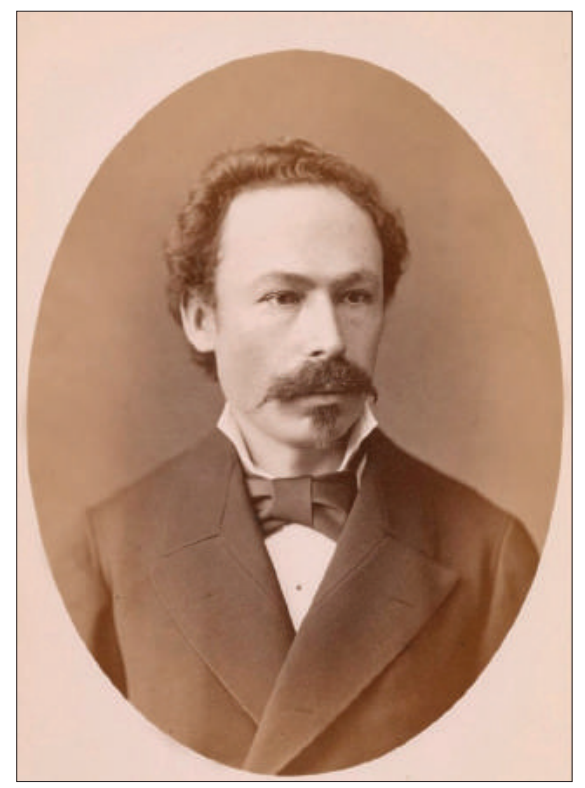

Ryc.1. Karol Olszewski (1846-1915)

Źródło: http://pauart.pl/app/artwork?id=BZS RKPS 7715 k 10

\section{Skroplenie gazów trwałych}

W lutym 1882 roku, dzięki przyznanemu przez Akademię Umiejętności stypendium im. Śniadeckich z funduszu Seweryna Gałęzowskiego, dr Zygmunt Wróblewski obserwował w Paryżu w laboratorium de l'Ecole normale H. Debraya podjęte przez Louisa-Paula Cailleteta próby skroplenia tlenu, azotu i innych gazów przy użyciu etylenu jako środka chłodzącego.

We wrześniu 1882 roku powrócił do kraju, uzyskał nominację profesorską, przejął po Stefanie Kuczyńskim Katedrę Fizyki Uniwersytetu Jagiellońskiego i podjął prace nad skraplaniem gazów. ${ }^{2}$

${ }^{1}$ Karol Olszewski, syn Jana i Anny ze Zwolińskich, urodził się 29 stycznia 1846 roku we wsi Broniszów koło Ropczyc. Po wybuchu powstania styczniowego porzucił szkołę i udał się do Krakowa, by przyłączyć się do oddziałów powstańczych. W trakcie szkolenia wojskowego został aresztowany i osadzony w więzieniu. Po uwolnieniu ukończył gimnazjum w Tarnowie, i w roku 1866 rozpoczął studia chemiczne na Wydziale Filozoficznym Uniwersytetu Jagiellońskiego. Był uczniem profesorów: Czyrniańskiego, Karlińskiego i Kuczyńskiego. Dzieje życia oraz osiągnięcia prof. Olszewskiego opisują liczne publikacje. Wymieńmy tylko kilka z nich: Wojtaszek i in. 1990; Szczepaniec-Cięciak 2000; Szytuła 2008; Góra 2013; Rafalska-Łasocha 2015.

2 Rafalska-Łasocha 2013, ss. 177-187. 
20 stycznia 1883 roku, na posiedzeniu Wydziału Matematyczno-Przyrodniczego Akademii Umiejętności, Wróblewski wygłosił referat pt. „O niektórych zjawiskach, jakie przedstawiają gazy i ciecze pod wysokim ciśnieniem, i najnowszych narzędziach do tego służących", co doprowadziło do podjęcia - od lutego 1883 roku - współpracy z profesorem chemii Karolem Olszewskim. ${ }^{3}$ Ich praca już po niespełna dwóch miesiącach została uwieńczona sukcesem: 29 marca udało im się skroplić tlen (ale bez uzyskania menisku; osiągnięto to ostatecznie 4 kwietnia), 13 kwietnia - azot, 19 kwietnia - tlenek węgla. ${ }^{4}$ 16 kwietnia 1883 roku telegram Wróblewskiego o skropleniu tlenu opublikowany został w Comptes Rendus - czasopiśmie Francuskiej Akademii Nauk (Wróblewski, Olszewski 1883a).

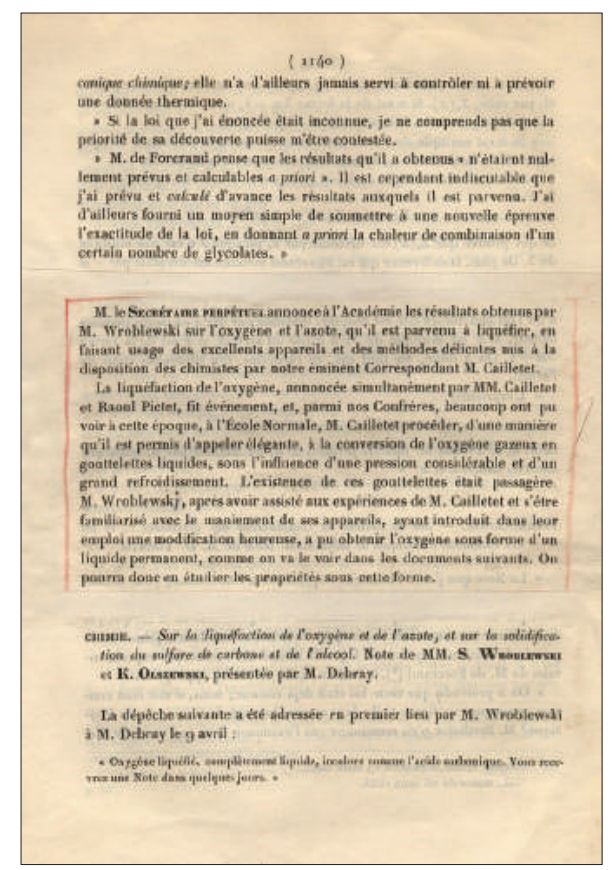

Ryc. 2. Comptes Rendus 96 (16 kwietnia, 1883), s. 1140

Źródło: http://jbc.bj.uj.edu.pl/Content/276684/obrazy/skropleniel.jpg

20 kwietnia Wróblewski i Olszewski przedstawili komunikat o skropleniu tlenu i azotu na posiedzeniu Wydziału Matematyczno-Przyrodniczego Akademii Umiejętności (Wróblewski, Olszewski 1883b), a trzy dni później telegram tych autorów na ten sam temat ukazał się w Comptes Rendus (Wróblewski, Olszewski 1883c).

Olszewski i Wróblewski zastosowali w prowadzonych eksperymentach własne, oryginalne rozwiązania, które w skromnych warunkach krakowskiego laboratorium do-

${ }^{3}$ Rafalska-Łasocha 2013, ss. 188-198.

4 Królas, Kucharski 2000, s. 432. 
prowadziły do uzyskania wyników, jakich przez lata nie udało się osiągnąć Cailletetowi w bogato wyposażonej pracowni. Sukces ten możliwy był dzięki zmodyfikowaniu pierwotnej metody Cailleteta. Odpowiednio niskie temperatury osiągnięto w Krakowie dzięki genialnym pomysłom i zdolnościom technicznym profesora Olszewskiego. ${ }^{5}$

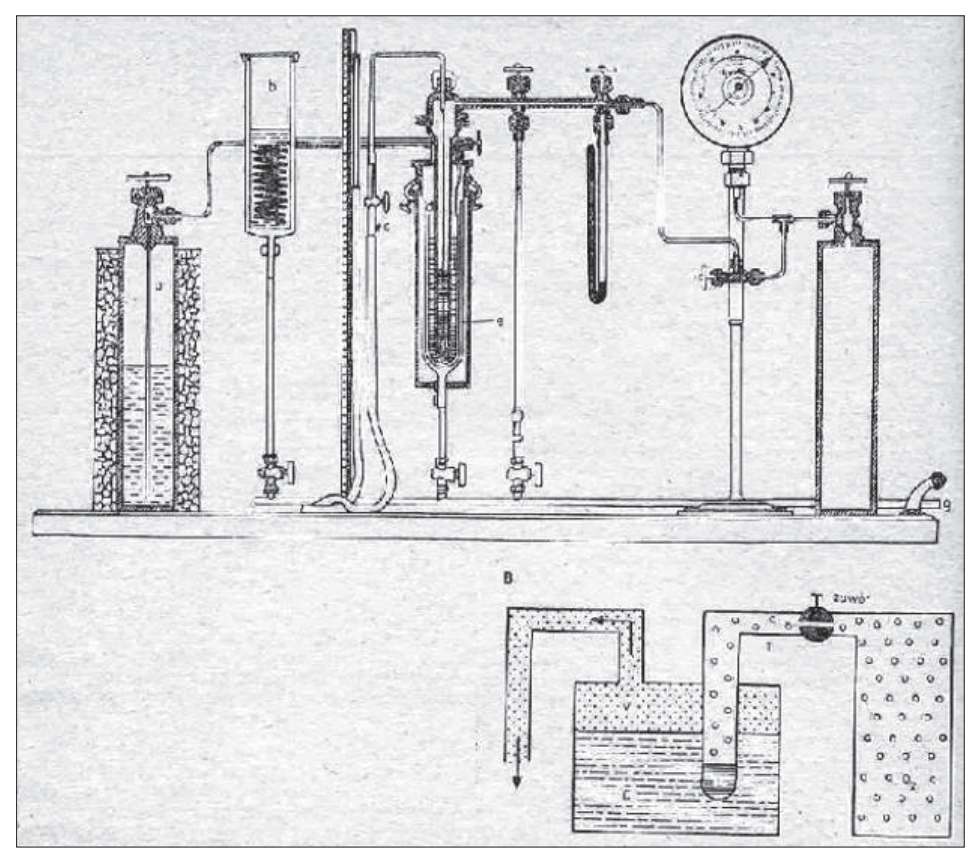

Ryc. 3. A: Schemat aparatury Wróblewskiego i Olszewskiego: a - butla z ciekłym etylenem; $\mathrm{b}$ - zbiornik z mieszaniną Thiloriera; c - termometr wodorowy; $\mathrm{d}$ - szklany zbiornik z ciekłym etylenem; e - grubościenna ampuła szklana, w której skrapla się gaz; f - stalowa butla z gazowym tlenem (p 60 atm); B: Ilustracja zasady działania aparatury Wróblewskiego i Olszewskiego.

\section{Źródło: Szytuła 2008, s. 54}

Sukces krakowskich uczonych odbił się szerokim echem na całym świecie. ${ }^{6}$ Współpraca Wróblewskiego i Olszewskiego trwała zaledwie kilka miesięcy, następnie prowadzili oni odrębne badania.

\section{Nie tylko kriogenika}

Olszewski uważany był za wybitnego eksperta w sprawach dotyczących urządzeń do badań niskotemperaturowych. Z dużym powodzeniem zajmował się konstrukcją aparatów do skraplania gazów, a nowoczesne skraplarki produkowane przez mechaników

\footnotetext{
${ }^{5}$ Rafalska-Łasocha 2013, s. 16.

${ }^{6}$ Wojtaszek i in. 1990, ss. 74-79.
} 
z Uniwersytetu Jagiellońskiego zamawiały i kupowały liczne instytucje badawcze w Europie i w Stanach Zjednoczonych.

Jednakże dokonania prof. Olszewskiego nie ograniczają się tylko do prac kriogenicznych. Niespełna miesiąc po ogłoszeniu przez Roentgena pracy o promieniach X profesor, wspólnie ze swoimi asystentami: Tadeuszem Estreicherem i Edwardem Drozdowskim, zbudował w Krakowie prosty przyrząd do wytwarzania tego promieniowania i na początku stycznia 1896 roku otrzymał promienie X oraz wykonał pierwsze zdjęcie rentgenowskie. ${ }^{7}$ Wkrótce, wspólnie z profesorem medycyny Alfredem Obalińskim, zastosował ten nowy rodzaj promieni do celów medycznych, a prace te dały początek polskiej radiologii. ${ }^{8}$

\section{Ożywione kontakty naukowe}

Olszewski, o czym świadczy obfita korespondencja, utrzymywał naukowe kontakty z największymi uczonymi swoich czasów: W. Ramsay’em, H. Kamerlinghem Onnesem, F. Haberem, J.H. van 't Hoffem, W. Ostwaldem, Lordem Rayleighem i W. Roentgenem oraz M. Skłodowską-Curie. ${ }^{9}$ Wśród wymienionych wszyscy otrzymali Nagrodę Nobla. Kraków nazywany był w tym czasie europejskim biegunem zimna, a pracownię Olszewskiego odwiedzali uczeni z całego świata. On sam z powodów zdrowotnych unikał zagranicznych podróży.

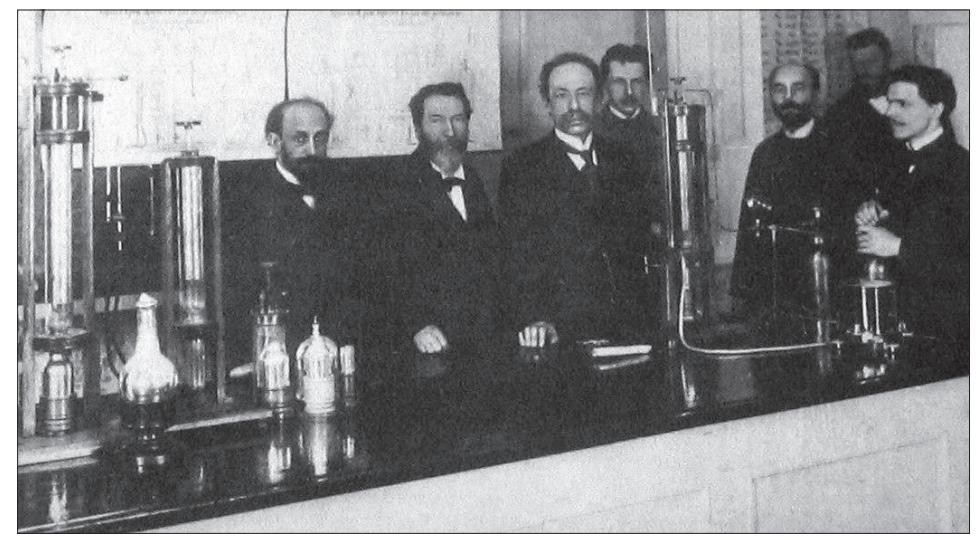

Ryc. 4. Wizyta R. Picteta w pracowni K. Olszewskiego w dniu 1 grudnia 1903 roku. Stoją od lewej: dr M. Altschul, prof. R. Pictet, prof. K. Olszewski, asystent S. Gizowski, mechanik W. Grodzicki, (w głębi malarz J. Stanisławski), dr T. Estreicher.

Źródło: Muzeum UJ

7 Urbanik i in. 2000, ss. 346-351.

${ }^{8}$ Leszczyński (red.) 2000, s. 93.

9 Rafalska-Łasocha 2015. (Część tej korespondencji zgromadzona jest w Muzeum UJ, a jej kopie w Archiwum UJ, w materiałach Zespołu Kriogenicznego UJ - dop. M.K.). 


\section{Uznanie naukowe}

Od 1888 roku profesor Olszewski był członkiem korespondentem Akademii Umiejętności w Krakowie, a od 1906 roku przewodniczącym jej III Wydziału Matematyczno-Przyrodniczego. Swoje oszczędności (140 000 koron w papierach wartościowych w 1908 roku i 45000 koron w 1913 roku) przekazał Akademii Umiejętności z przeznaczeniem na rozwój badań naukowych w dziedzinie niskich temperatur. Kolejną darowiznę, 2900 koron oraz przyrządy do skraplania gazów, przeznaczył na „pierwsze urządzenie muzeum przyrodniczego lub kryogenicznego".

Był też członkiem honorowym wielu zagranicznych towarzystw naukowych i uhonorowano go licznymi nagrodami. Kilkakrotnie nominowano go do Nagrody Nobla w dziedzinie fizyki lub chemii. Co prawda jej nie otrzymał, lecz H. Kamerlingh Onnes (laureat Nagrody Nobla z fizyki w 1913 roku) w mowie wygłoszonej w Sztokholmie podkreślił zasadnicze znaczenie prac Olszewskiego i Wróblewskiego w dziedzinie badań w niskich temperaturach. ${ }^{10}$

\section{6. Śmierć Olszewskiego}

Karol Olszewski zmarł 25 marca 1915 roku. Depesze kondolencyjne wysłano do Krakowa z Wiednia, Pragi, Insbrucku, Heidelbergu, Budapesztu, Paryża, Bolonii, Rzymu, Genewy, Bazylei, Lozanny, Neapolu, Montpellier, Liverpoolu, Leeds, Manchesteru, Toronto i Kyoto. W prasie i w specjalistycznych czasopismach, zarówno w kraju, jak i za granicą, ukazało się wiele wspomnień pośmiertnych.

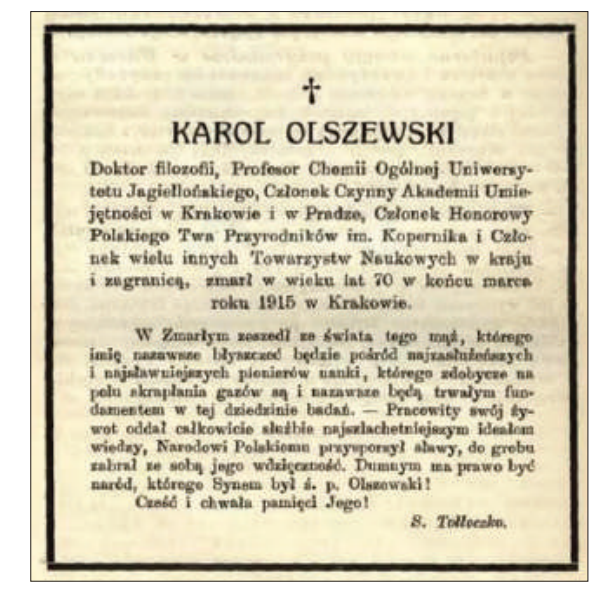

Ryc. 5. Nekrolog po śmierci prof. Olszewskiego

Źródło: KOSMOS 1915 40(1/6), s. 208; http://www.sbc.katowice.pl/dlibra/docmetadata?id=30835

${ }_{10}$ Wojtaszek i in. 1990, s. 129. 
Pojawiały się one również i później, najczęściej z okazji rocznic skroplenia gazów trwałych lub innych wydarzeń związanych z życiem i działalnością profesora Olszewskiego. W dziesięciolecie śmierci profesora Tadeusz Estreicher, jego uczeń i następca, napisał:

Olszewski był, jak to podniósł Smoluchowski w swojem pięknem i głęboko ujętem wspomnieniu po nim [mowa tutaj o artykule prof. Mariana Smoluchowskiego pt. «Karl Olszewski - ein Gelehrtenleben» wydrukowanym w 1917 roku w Die Naturwissenschaften], doskonałym reprezentantem typu uczonego, zwanego przez Ostwalda klasycznym: powoli, ale wytrwale i metodycznie w wybranym przez siebie kierunku pracującym badaczem, który nigdy nie ogłasza nic przedwczesnego, nic niedojrzałego, i nie da się odciągnąć z drogi do wytkniętego celu przez żadne postronne zagadnienia, chociażby go nawet najbardziej zajmowały. Typ taki jest, szczególniej wśród Polaków, impulsywnych na ogół i skorych do nagłego, a niestety często niedługotrwałego entuzjazmu, rzadki. Możemy być dumni, że się wśród nas zjawił i działalnością i sławą swoją rzucił odblask chwały na naukę polską. ${ }^{11}$

\section{Obchody 100. rocznicy śmierci profesora Olszewskiego}

W stulecie śmierci profesora Olszewskiego Wydział Chemii Uniwersytetu Jagiellońskiego przygotował wspomnienie wielkiego uczonego. Część organizacyjna obchodów tej rocznicy spoczywała na barkach Biura Karier i Promocji Wydziału Chemii UJ. W Auli Jagiellońskiej Collegium Maius Muzeum UJ, sąsiadującej z gmachem przy ul. Olszewskiego 2, gdzie żył, pracował i zmarł Olszewski, w przeddzień rocznicy śmierci profesora odbyło się uroczyste spotkanie. Rozpoczęła je dziekan Wydziału Chemii UJ, prof. Grażyna Stochel, wspólnie z dyrektorem Muzeum dr. hab. Krzysztofem Stopką, prof. UJ, witając przybyłych gości.

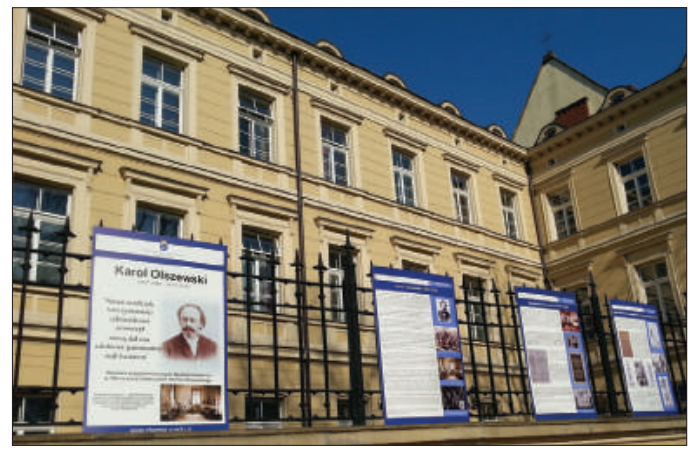

Ryc. 6. Wystawa planszowa poświęcona Karolowi Olszewskiemu przy ulicy Olszewskiego 2, gdzie mieszkał, pracował i zmarł prof. Olszewski, i gdzie mieściło się Collegium Chemicum

Foto: A. Rafalska-Łasocha

${ }_{11}$ Estreicher 1925, ss. 36-37. 
W programie uroczystości znalazły się wystąpienia studentów („Profesor Karol Olszewski jako wzór dla młodego pokolenia”, Gabriela Handzlik, prezes NKCh) i pracowników Wydziału Chemii („Profesor Karol Olszewski - uczony i nauczyciel”, prof. dr hab. Andrzej Kotarba). Uczestnicy obejrzeli również kolekcję instrumentów naukowych ze spuścizny po prof. Karolu Olszewskim i wystawę na Plantach (ul. Olszewskiego 2) pt. „Profesorowi Karolowi Olszewskiemu w 100-lecie śmierci”.

Na zakończenie uroczystości zebrani udali się na cmentarz Rakowicki, gdzie na grobie profesora Olszewskiego (pas 9.) złożyli wiązanki kwiatów.

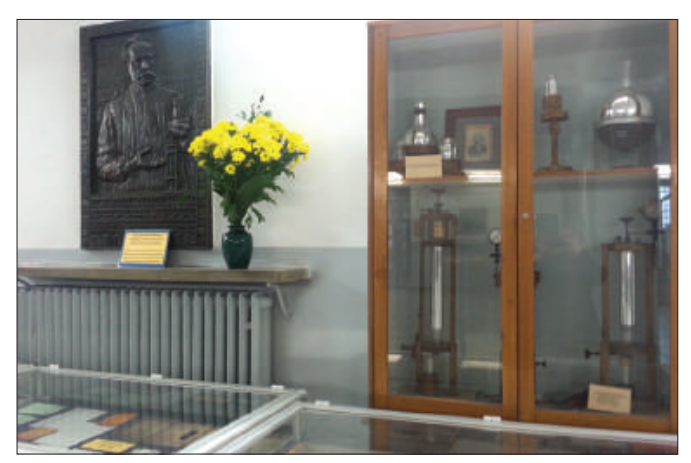

Ryc. 7. Pamiątkowa tablica poświęcona Karolowi Olszewskiemu i fragment okolicznościowej wystawy na Wydziale Chemii UJ w Krakowie, ul. Ingardena 3

Foto: A. Rafalska-Łasocha

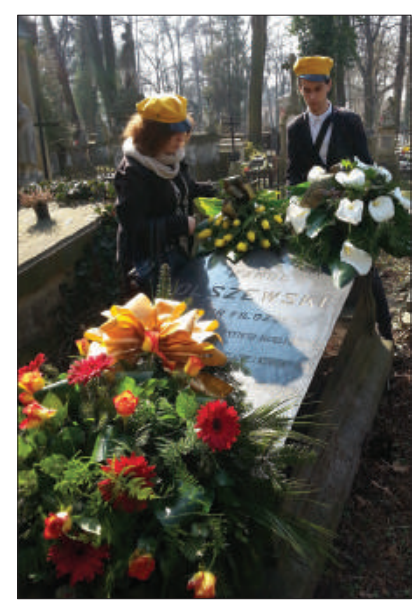

Ryc. 8. Uroczyste złożenie kwiatów na grobie prof. Karola Olszewskiego na cmentarzu Rakowickim w 100. rocznicę jego śmierci

Foto: A. Rafalska-Łasocha 


\section{BIBLIOGRAFIA}

ESTREICHER Tadeusz

1925: Karol Olszewski w dziesięciolecie śmierci (Kraków: Drukarnia „Czasu”; Odbitka z Przegladu wspótczesnego nr 37 i 38), ss. 37.

GÓRA Paweł F.

2013: Zygmunt Florenty Wróblewski, pionier kriofizyki. Publikacja dostępna online: http://th-www.if.uj.edu.pl/zfs/gora/varia/wroblewski.pdf.

KRÓLAS Krzysztof, KUCHARSKI Maciej

2000: Zygmunt Florenty Wróblewski (1845-1888). [W:] Złota Księga Wydziału Matematyki i Fizyki pod redakcją Bolesława Szafirskiego (Kraków: Wydawnictwo Uniwersytetu Jagiellońskiego), ss. 429-434.

LESZCZYŃSKI Stanisław

(red.) 2000: Historia radiologii polskiej na tle radiologii światowej. Kraków: Medycyna Praktyczna.

PAWŁOWSKA Maria, WICHMAN Jadwiga

2013: Wystawa wirtualna „Ty, co lotne ściskasz gazy, że aż marzną wśród szklanicy...”. Opracowanie wersji cyfrowej: Joanna Hoły. Elementy graficzne udostępnił: Nikodem Frodyma. Publikacja dostępna online: http://jbc.bj.uj.edu.pl/Content/276684/ index.html.

RAFALSKA-ŁASOCHA Alicja

2013a: Zygmunt Florenty Wróblewski (1845-1888). [W:] Wielcy Polacy z Galicji i Kresów Południowo-Wschodnich, (Białystok: Wydawnictwo Buk), ss. 177-187.

2013b: Karol Stanisław Olszewski (1846-1915) z Broniszowa k. Ropczyc. [W:] Wielcy Polacy $z$ Galicji i Kresów Południowo-Wschodnich. Białystok: Wydawnictwo Buk, ss. $188-198$.

2013c: 130th anniversary of the liquefaction of solid gases at Jagiellonian University. Newsletter JU 16, p. 16. Publikacja dostępna online: http://www.uj.edu.pl/ documents/1333512/2818db1d-f59a-491f-9fa6-13410499aab3.

2015a: Wspomnienie w 100. rocznicę śmierci Karola Olszewskiego. Alma Mater 175-176, ss. $44-48$.

2015b: Maria Skłodowska-Curie i jej kontakty ze środowiskiem krakowskim. Kraków: Polska Akademia Umiejętności.

SZCZEPANIEC-CIĘCIAK Elżbieta

2000: Karol Olszewski (1846-1915). Chemik, światowej sławy kriogenik. [W:] Złota Księga Wydziału Chemii, tom I, pod redakcją Elżbiety Szczepaniec-Cięciak (Kraków: Wydawnictwo Uniwersytetu Jagiellońskiego), ss. 144-151. 


\title{
SZYTUŁA Andrzej
}

2008: 125. rocznica skroplenia składników powietrza. Alma Mater 108, ss. 53-57. Publikacja dostępna online: http://www2.almamater.uj.edu.pl/108/16.pdf.

URBANIK Andrzej, BORCZOWSKA Elżbieta, CHOJNACKA Irena, HERMAN-

-SUCHARSKA Izabela, CHRZAN Robert, KUŚMIDERSKI Józef

2000: Początki radiologii w Krakowie. [W:] Historia radiologii polskiej na tle radiologii światowej pod redakcją Stanisława Leszczyńskiego (Kraków: Medycyna Praktyczna), ss. 346-351.

\section{WRÓBLEWSKI Zygmunt}

1883: O niektórych zjawiskach, jakie przedstawiają gazy i ciecze pod wysokim ciśnieniem, i najnowszych narzędziach do tego służących. Rocznik Zarządu Akademii Umiejętności w Krakowie 1883 /1884.

WRÓBLEWSKI Zygmunt, OLSZEWSKI Karol

1883a: Sur la liquéfaction de l'oxygène et de l'azote, et sur la solidification du sulfure de carbone et de l'alcool. Note de MM. S. WROBLEWSKI et K. OLSZEWSKI, présentée par M. Debray. Comptes Rendus 96, s. 1140. Publikacja dostępna online: http:// jbc.bj.uj.edu.pl/dlibra/docmetadata?id=235123.

1883b: Sur la liquéfaction de l'azote. Note de MM. S. WROBLEWSKI et K. OLSZEWSKI, présentée par M. Debray. Comptes Rendus 96, s. 1225-1226. Publikacja dostępna online: http://jbc.bj.uj.edu.pl/dlibra/docmetadata?id=235125.

WOJTASZEK Zdzisław, KUZYK Halina, MORZYNIEC Alojzy, DUBOWY Jerzy, ŁOPATA Krystyna

1990: Karol Olszewski. Warszawa-Kraków.

\section{KAROL OLSZEWSKI'S 100TH ANNIVERSARY OF DEATH AND HIS CONTRIBUTION TO CRYOGENICS}

\begin{abstract}
The article briefly presents the scientific achievements of Karol Olszewski (1846 -1915), who was born when Poland did not exist on the map of Europe and Polish science was developed mainly in Krakow, Lviv and at some European Universities. In 1883 Karol Olszewski and Zygmunt Wróblewski were the first in the world to liquefy oxygen, nitrogen and carbon oxide from the atmosphere in a stable state. In 1884 Olszewski was also the first person who liquefied hydrogen in a dynamic state, achieving a record low temperature of $225^{\circ} \mathrm{C}(48 \mathrm{~K})$. In 1895 he succeeded in liquefying argon.
\end{abstract}


In January 1896 Olszewski replicated the Roentgen's set-up for obtaining X-rays and successfully obtained this newly-discovered radiation for the first time in Krakow, initiating the foundation of the university's department of radiology.

Olszewski died on 25 March 1915. In March 2015 the Faculty of Chemistry of the Jagiellonian University organized a special celebration to commemorate the life and achievements of Karol Olszewski.

Keywords: Karol Olszewski, cryogenics, history of science 